\title{
PROSPECTS FOR BUSINESS INTELLIGENCE DEVELOPMENT IN THE LATVIAN BUSINESS ENVIRONMENT
}

Oskars Onzevs ${ }^{1}$, Dr. sc. ing., assistant professor; Gita Kolerte ${ }^{2}$, MBA

\begin{abstract}
Business intelligence (BI) is a specific service niche that is developing very rapidly. The aim of the study was to identify the development opportunities of Latvian BI service companies in Latvia market. It has been ascertained that medium and large companies globally need BI systems and sometimes even small companies need it, but it depends on the particular business field, the amount of data analysed and other factors. In Latvia, there are only $1.07 \%$ of such enterprises - in general, 1603 (0.93\%) medium-sized enterprises and only $238(0.14 \%)$ large enterprises. It should be taken into account that many companies have already introduced BI or similar analytical solutions, so forecasts about the acquisition of the local market and the existence of free niches can be said to have been already exhausted. Also, the saturation of the local market with similar business analytics services offered by ICT service providers should be taken into account. Therefore, in order to keep up the pace of growth and prevent stagnation of business processes, BI service providers must devise relevant strategies for businesses to enter into external markets.
\end{abstract}

Key words: Business Intelligence (BI), Information and Communication Technologies (ICT), development prospects.

JEL code: M15

\section{Introduction}

Today's business is all about data and the way that an entrepreneur can use data effectively to promote their business growth. For every business, small and medium-sized as well, the amount of data today is greater than ever. Every modern company accumulates a large amount of data on a daily basis - about customers, suppliers, competitors, units sold, their prices, discounts, changes in volumes, earnings figures, profit and loss accounts at different time intervals and many other different types of data. On a daytoday basis they are stored in various information resources. These data are vital for business development of the company.

The number of companies operating in the IT sector is increasing every year. Growing export volumes, well-paid jobs with a growing trend in the number of employees in the sector and the arrival of new companies in the sector indicate the breakthrough in the development of the IT industry. The various start-up companies and innovation technologies in the IT industry have been progressing and developing quite rapidly over the past few years, which makes competition increasingly saturated and intense. Although business intelligence is only a small part of the overall IT service basket, it is important to take into account the fact that in recent years new competitors are emerging on the market offering similar services, and large players in the industry tend to expand their range of services by including BI services.

Assessing BI development in the Latvian business environment in depth is a challenge that is both possible and impossible at the same time. Though globally, this area is evolving, business niche players are largely guided by their experience and inner feelings. Paid market research does not help in getting accurate information and only direct communication with each of the company representatives helps. It is only when speaking personally that one can determine whether the company is ready to implement BI systems in its daytoday operations. Often this is a question of corporate ambitions, finances and internal culture. However, in order to highlight the current situation, the authors evaluate the nature of the commercial enterprises active in this field and have conducted additional research by interviewing industry experts.

Research environment: Latvian BI service providers.

Research object: development prospects of Latvian BI service providers in the Latvian market. 
Hypothesis: the Latvian market is too small for BI service companies to maintain growth and keep business processes ongoing.

Aim of the paper: to study the development prospects of Latvian BI service companies in the Latvian market.

The research tasks to be achieved in order to achieve the goal: 1.to explore the role of ICT and BI services in the economy of Latvian; 2. to explore possibilities of developing BI services in the Latvian market.

The study was conducted over the period 2016-2017. The research framework was organized as follows. The monographic method is used to compile existing scientific knowledge. Using the available statistical databases data was obtained. Data are analysed using a graphical and comparative method. In-depth interviews were used to confirm the results of the research of statistical data and the authors' point of view. Two expert interviews were conducted: with Karlis Vitols (Vitols, K., 2017), Chairman of the Board of "Scandic Fusion", 2) with Ainars Bemberis (Bemberis, A., 2017), country manager of "SAP Latvia".

\section{Research results and discussion}

The chaotic term 'Business Intelligence' has been in use since the 1860s, however, in 1989, consultant Howard Dresner made the first suggestion of using this term as a main term for all categories related to data analysis methods and business decision making processes (TechTarget, 2014). From the technology side of $\mathrm{BI}$, one definitely needs to mention separate tools provided by industry players like Oracle, SAP Qlik and Microsoft that are among the largest and most leading providers of data analysis platforms in the world. BI data can include historical data information, and also new data collected from different source systems. Originally, BI tools were only used by analysts and IT technicians in practice, but nowadays the portals have been upgraded to make it easy for simple users to work with them (Hocevar B., Jaklic J., 2010).

The BI field is a relatively specific business niche, because in essence it relates to not only the IT industry, but also combines system analysis and the ability to go deep into the specifics of the client's business. It is not just the next level of information technology development beyond simple software development and implementation or interpretation of communications or technology in another dimension. Business intelligence includes a wide range of analytical knowledge sets, as well as specialized tools for designing and configuring knowledge (Alaskar T., Efthimios P., 2015). Today, businesses and the business environment are much more developed than they were over the last ten years. Managers are knowledgeable and demanding about their business, as well as know where to go and what they want to achieve and, above all, how to achieve it. As a result, the characteristics of BI customers are not typical of a segment and are more complex than the breakdown of the simple (typical) segmentation criteria. The most important nuance in business intelligence is the client's understanding of BI in general and the desire to implement it in their businesses.

\section{The role of ICT and BI services in the Latvian economy}

Export performance of the ICT industry, which continues to grow with each passing year is an extremely important macroeconomic indicator. Although Latvia ICT market is relatively limited and the major customers are state and municipal institutions that need specific solutions, IT service exports are the fastest growing sector in Latvia during the post-crisis period. Since 2010, the sector's exports have grown on average by $23 \%$ per year, and the total volume of services 
provided is increasing year by year. In 2016 and 2015, the export of Latvian IT services, according to the Bank of Latvia data, increased by $30 \%$, while our country's economy grew by only as much as $2 \%$. Exports of IT services in 2016 accounted for $2.3 \%$ of the total exports of Latvia's goods and services. Assessing the World Trade Organization (WTO) data in the IT service sector, there is a tendency for Latvia to globally export ICT services more than directly import, and the volume of exports is only continuing to grow (see Figure 1). Since 2010, IT services have grown by as much as $300 \%$ (!) and referring to Certus annual report on the industry for 2014 , the main IT service export markets were the United States (10.2\%), Cyprus (9.1\%), Sweden (9.1\%) and Great Britain (5.1\%) (Kreslins K., Meijere S., 2016). The ICT sector as a whole, in 2015, compared with the previous year, increased its exports by $1.1 \%$ (services - $9.8 \%$ ), which in monetary terms was estimated at 114.6 million (services - 36.5 million).

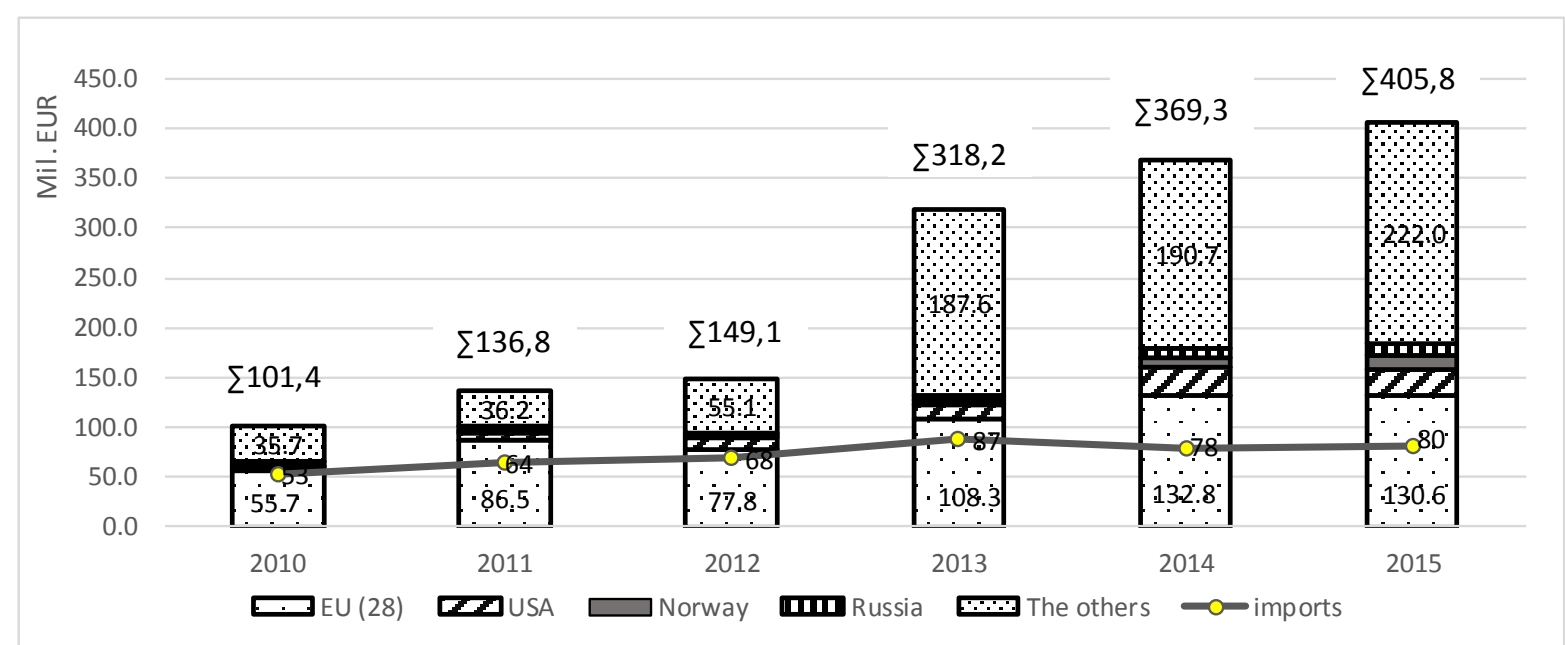

Source: World Trade Organisation

Fig. 1. Comparison of Latvian IT service export and imports, mil. EUR

Export volumes of ICT industry services in the third quarter of 2016 compared to the same period in 2015 increased by $40 \%$, reaching a total of 143.82 million including exports of goods and services as indicated by the latest data from the Bank of Latvia. Latvian exports of ICT services showed even more growth, in 2017, and currently the existing indicators can be compared with the export rates of rail transport and financial services.

Although the field of ICT is a rather broad definition of the sector, the statistics of the Latvian sector are reflected in common figures and data are not divided in detail, categorising business intelligence as a separate group. The indicators of the BI industry are included in the total statistics depending on the NACE 2 classification of economic activities specified by the enterprises while submitting periodic statistical reports. For example, usually companies identifies itself to the group 62.01 - Computer Programming, which is in the $62^{\text {nd }}$ overall group with relevance to "Computer Programming, Consultancy and Related Activities", although Group 63.11 "Data Processing, Maintenance and Related Activities" also includes operations related to data processing and provision of advice (CSB, statistical classification). Since the breakdown is not structured according to the required industry, the data should be treated as a provisional representation of the share of the industry. However, the main trends in the sector as a whole as reflected in Figure 2 show the rapid growth and dynamic development of the ICT sector in recent years. The apparent development dynamics of the particular industry show the rapid development trend of companies in the NACE group 62.01. The industry's growth indicators are record-breaking - that is, over a 
decade from a few companies, the market segment has become oversaturated and now the number of companies is over 2135. Just over the last year, the number of companies has grown rapidly, with a growth of more than 576 new businesses (36.9\%). The NACE 62.01 group consists of all companies whose core business involves software development, IT infrastructure provision and related services (CSB, 2017). Although the provision of business intelligence services involves the development of the core business and is part of this group, consultancy is also service provided. So, the authors would like to emphasize that this sector should, however, be subdivided into a separate subsector, since at present it often confuses the industry, at the time of submission of statistics.

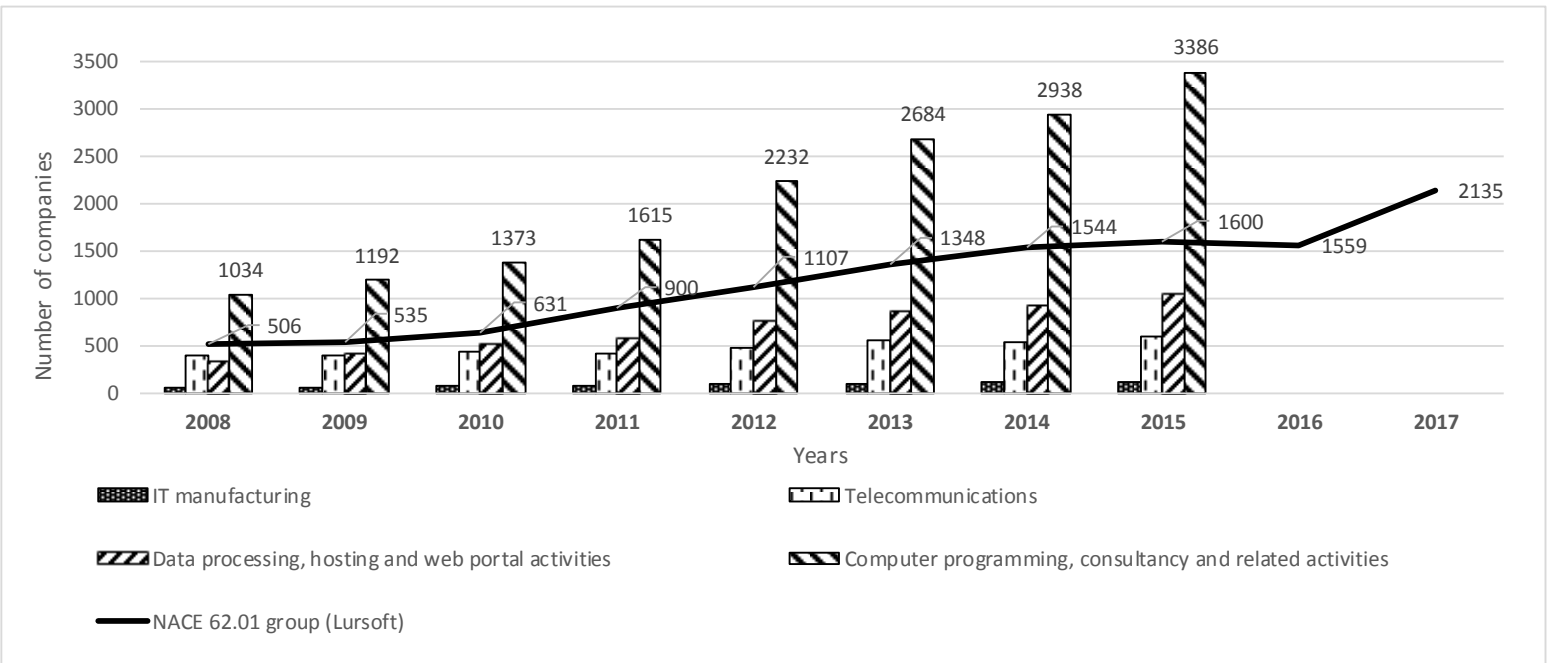

Source: Central Statistical Bureau of Latvia; Lursoft

Fig. 2. The dynamics of the number of enterprises for the ICT subsectors in Latvia

According to the data of the Central Statistical Bureau (CSB) of the Republic of Latvia, the growth of IT industry development has increased year by year and now in Latvia, there are more than 6133 companies operating in ICT, of which 3386 (more than half of all companies in the sector) are directly involved in software development, provision of consulting services, data processing, maintenance etc. The ICT sector grew by $94.6 \%$ over the period of 5 years, from 2010 to 2015 (12.9\% over the last year), while the number of programming and consulting services increased 2.5 times, or their number increased by $146.6 \%$ for the same period ( $15.2 \%$ in the last year and 3.2 times since 2008). The ICT industry is most active in the field of computer software and consulting, but the industry is multifaceted and includes services such as IT manufacturing and data processing, maintenance and operation of Internet portals, as well as telecommunications, equipment repair etc. Lattelecom, Tieto Latvia, Accenture, Exigen Services, LMT, Mikrotiks, C.T.Co., Draugiem Group and many others are leading companies in the ICT industry.

The total turnover of the ICT industry is extremely important not only for each company individually but also for the growth of the country as a whole. Since 2009, the sector has grown more and more, which is reflected in the turnover figures. For example, in 2015 the total ICT sector turnover reached 3.5 billion. EUR, of which more than 536 million were directly from software development consulting services (Fig. 3). Accordingly, the total turnover of the sector increased by $14.1 \%$, but in the area of programming and consulting services, the increase was $13.8 \%$ compared to the previous year. At the same time, profit margins for the sector increased 
by $11.7 \%$ overall in 2015 , whereas profit margins increased by $13.3 \%$ in the programming and development sector separately, compared to 2014.

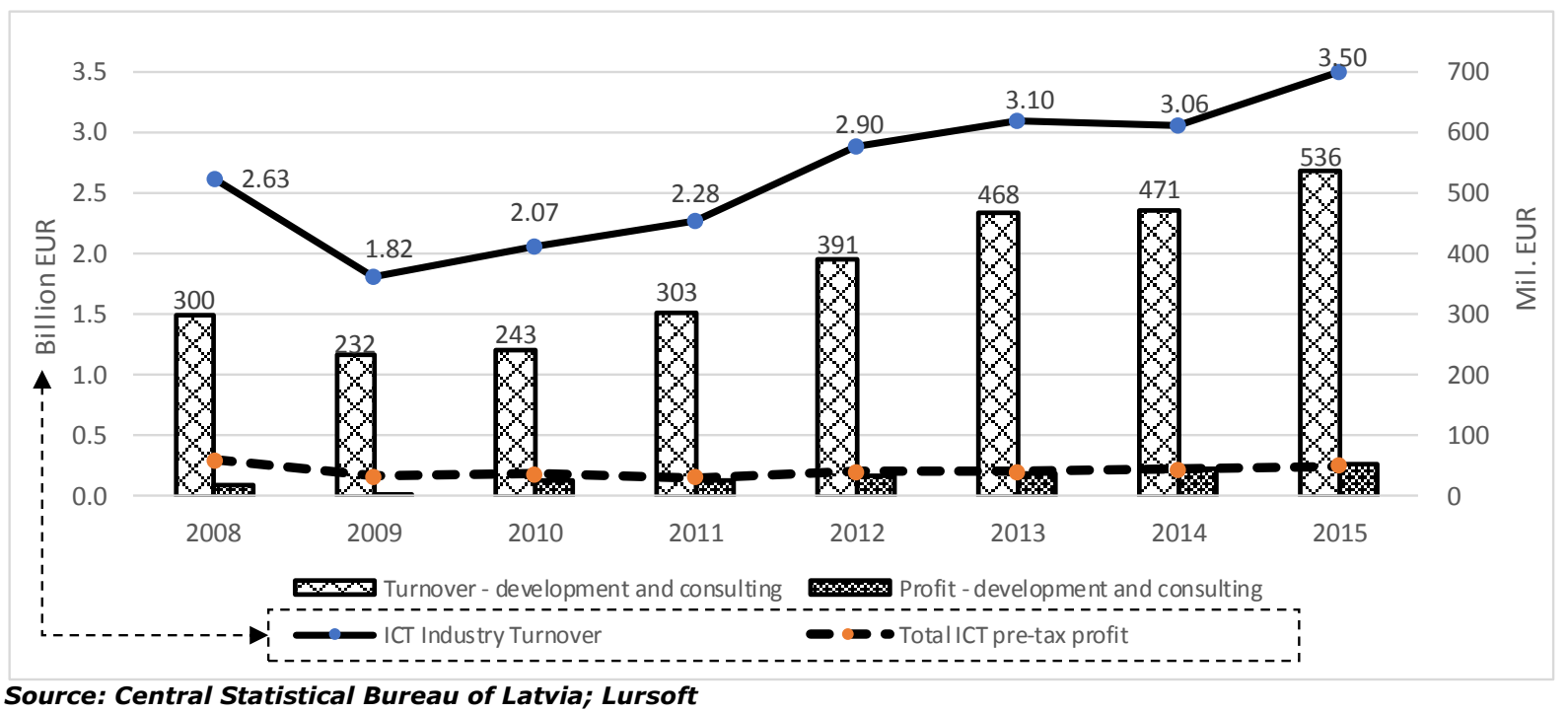

Source: Central Statistical Bureau of Latvia; Lursoft

Fig. 3. The Latvian ICT sector turnover, EUR

Meanwhile, the number of people employed in the programming and service sector in 2015 was 13423 and 29203 in the sector as a whole, which is a share of only $2 \%$ of the total number of people employed in Latvia. However, at present, the proportion of ICT specialists in Latvia is lower than the average number of employees in the EU. The number of employed resulted in 472 million Euro as personnel costs, and tax revenues generated by the State Revenue Service (SRS) amounted to 42 million Euro. (CSB, 2017). The NACE group 62 makes an annual contribution in average of more than 100 million per year in taxes to the state budget, reaching 140.16 million euros in 2016. The share of the ICT sector's added value in the gross domestic product in 2015 reached $4.2 \%$. The sector is characterized by a steady increase in export volume not only in absolute terms, but also in the share of exports of all total services provided, which is why it is the high time that companies devote all their efforts on developing export markets.

\section{Development of BI services in the Latvian market}

According to data provided by the CSB and the Ministry of Economics of the Republic of Latvia, in 2013 there were 155'130 economically active enterprises in Latvia, whereas in 2015 there were already 172'567 - individual merchants and commercial companies, including not only merchants, but also farmers, fishermen households and self-employed persons engaged in economic activities. The Latvian business environment is mostly characterized by micro-enterprises $(93.7 \%, 2015)$ and small enterprises $(5.29 \%, 2015)$, which fall under the SME category (Figure. 4).

BI's prospects for today's situation will be characterized by an excerpt from the interview with Chairman of the Scandic Fusion (Vitols, K., 2017):

"Looking in depth BI consists of data analysis, planning and artificial intelligence. Today there are no customers who do not do any analytics. Data is there and it already exists in some form, mostly in MS Excel files. But this is just one part of the needs of all customers, so if the prospects are to be said, then I definitely see them in the second and third segments - in the area of planning and artificial intelligence - companies will increasingly want to closely plan their planning processes and will closely want to integrate probability forecasts for events tomorrow, evaluating the most appropriate for each company and its needs, using the software. Data analysis was what 
we started with - now the niche is already exhausted or close to that which is in tune with the number of large companies in Latvia."

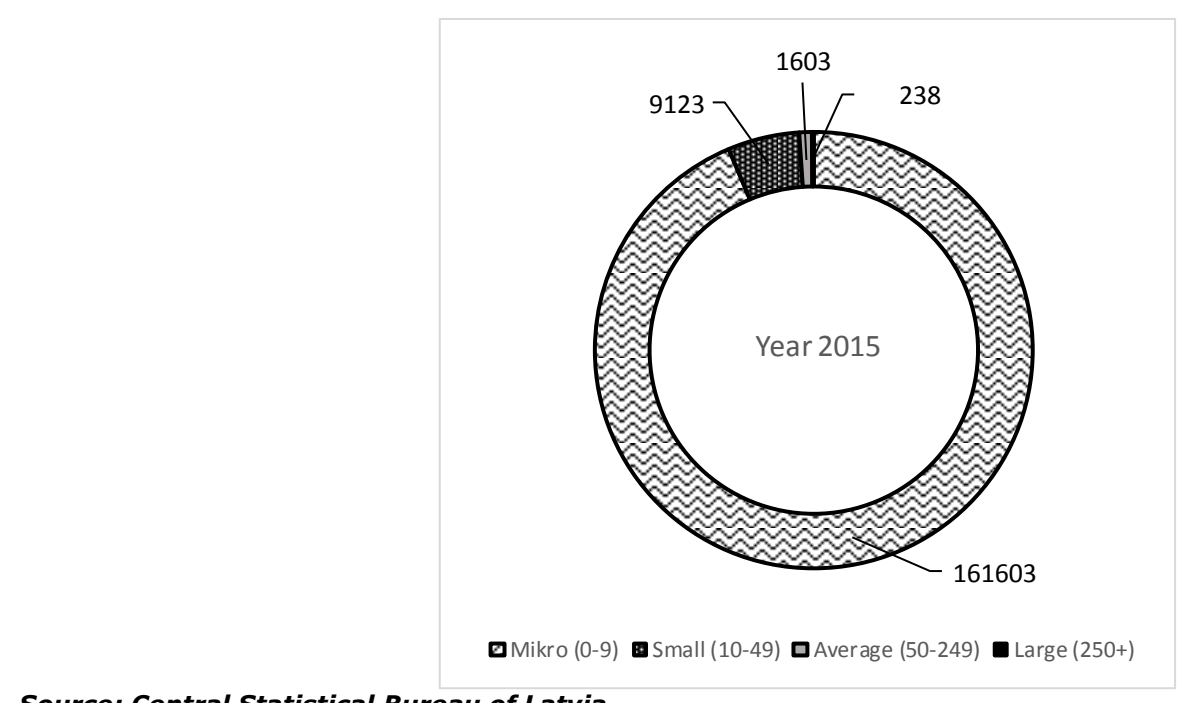

Source: Central Statistical Bureau of Latvia

Fig. 4. Economically active enterprises in Latvia (2015)

Taking into account the fact that it is precisely the medium and large companies that are most in need of business analytics, it is concluded that the market niche is significantly limited. According to CSB data for 2015, it can be concluded that in Latvia there are only $1.07 \%$ such enterprises in general - $0.93 \%$ average sized companies and only $0.14 \%$ of large enterprises. Of course, this is general information, but it should be taken into account that many companies have already introduced a BI or a similar analytical solution. However, if we evaluate the situation at the national level on how many companies in different sectors in Latvia are there purely statistically, then we can conclude that the sectors differ - some have considerably more companies, while others have considerably higher turnover and profit indicators than the former.

Figure 5 more specifically highlights BI potential clients in the corporate sector, only medium and large companies (CSB, 2017). In Latvia, there are only 31 enterprises operating in the field of insurance ( $38 \%$ or 12 of them meet the criteria for medium and large companies by number of employees) and 633 financial service providers (5.4\% or 34 of them medium and large), while the other 1290 enterprises in this combined category are financial services and involved in activities complementary to insurance activities. This means that the company is affiliated with the financial sector and / or insurance, but does not directly provide these services, but acts as an affiliated company in order to enable the key players in the sector to realize their direct business. 


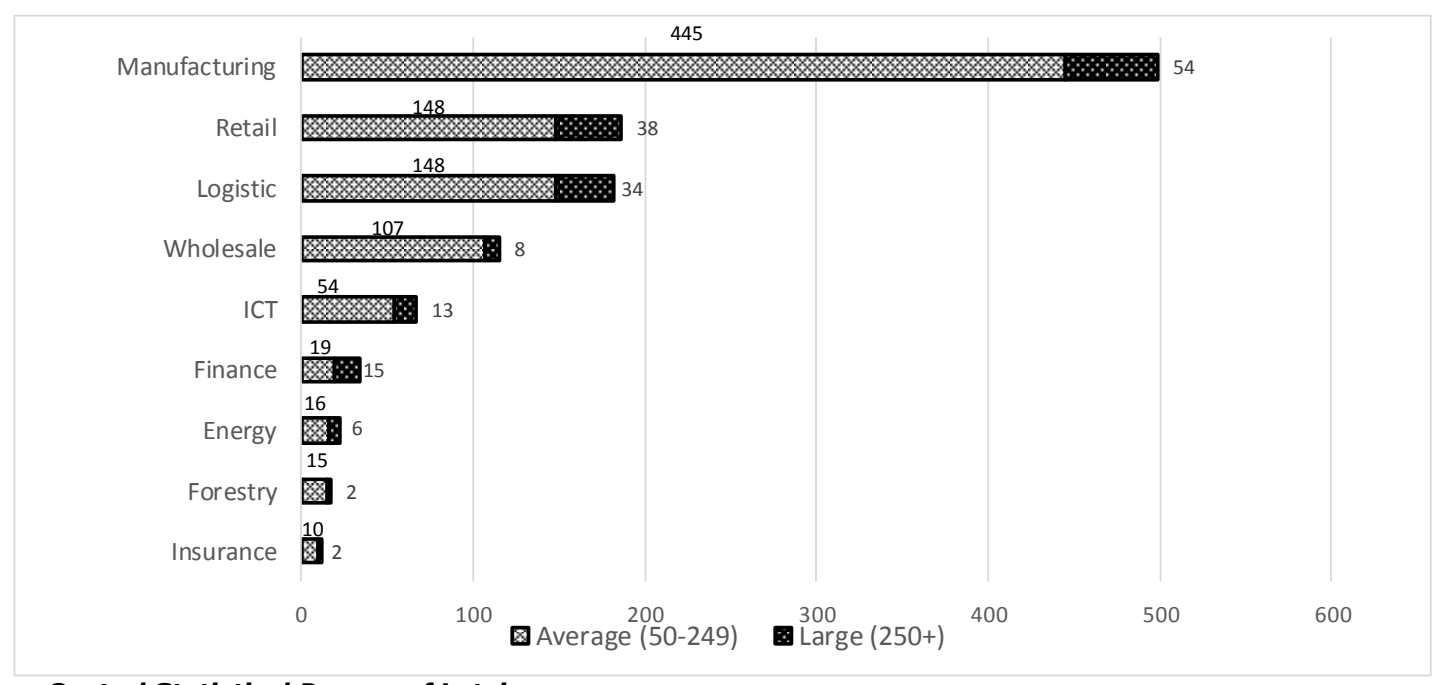

Source: Central Statistical Bureau of Latvia

Fig. 5. Number of medium and large sized companies in certain specific spheres in (2015)

Business intelligence services are needed for companies that have large and "growing" data, so that employees can no longer process them in time and the company is no longer able to process critical information necessary for business with MS Excel tables. This means that the companies most often are "medium" or "large" enterprises and such companies with the most turnover often operate in the retail, energy, transport and ICT sectors. If we look at the information available through CSB, taking into account only the number of employees or turnover figures, the authors believe that such enterprises can only be classified in such a manner to be structured into generally accepted categories, and certainly not to determine whether a company definitely needs a BI solution or not. Referring to an interview with the Chairman of the "Scandic Fusion", a leading BI expert (Vitols, K., 2017), a "small" company with a small number of employees can also generate a turnover of several million euros a year. The introduction of business intelligence services totally depends on the client's business specifics, the amount of data, the need and the desire to improve business processes. Although the BI niche is globally promising and is only beginning to evolve, for example, it is an obvious part of every banking system, insurance, energy sector companies and its necessity is already evident today in other sectors. However Latvian market is too small. At the same time, the BI sector is developing and new competitors are entering the market, and the future scenario of growth prospects within the Latvian market alone is not promising. The growth of the sector has been considerable in recent years and development is still ongoing (Evans J. R., 2015). Comparison of direct BI competitors in Latvia is given in Figure 6.

From an interview with Ainars Bemberis (Bemberis, A., 2017), it follows that data is increasingly being stored globally and demand for their use is only rising. Karlis Vitols (Vitols, K., 2017) sees his company have been involving in North European and European companies.

In order to not just maintain the current level of achievement, but also promote the growth of the company, BI service providers need to consider the conquest of external markets and the provision of service exports, focusing on Scandinavia or other financially sound countries. 


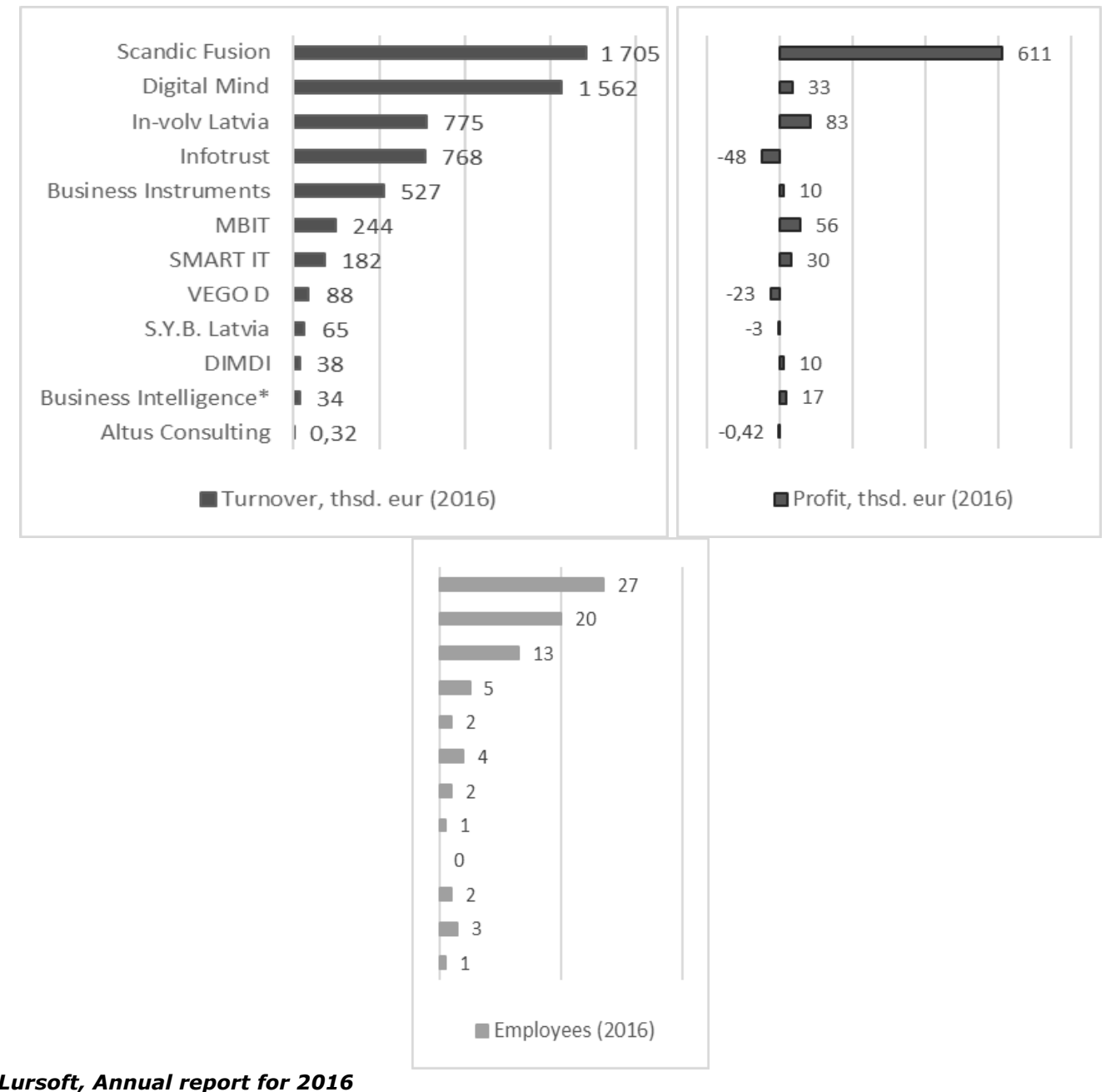

Fig. 6. Comparison of direct competitors according to turnover, profit and number of employees

\section{Conclusions, proposals, recommendations}

1) The increasingly digitalization of sectors worldwide also contributes to the growth of the IT sector - new products and services are being created. Since 2010, export of IT services has grown by $300 \%$ overall.

2) Evaluating World Trade Organization (WTO) data in the IT service sector, one can observe a trend that Latvia globally exports more ICT services than it directly imports and the volume of exports is only continuing to rise. The number of enterprises in Latvia that need BI systems is limited.

3) ICT sector development indicators for Latvia are at a record-breaking level, i.e. over a tenyear period from just a few companies, the market segment has become saturated and at present there are more than 2135 companies operating in this sector.

4) The following companies are definitely worth mentioning as leaders in the ICT market with the following turnover in 2016: SIA Tieto Latvija (39.38 mln.eur), Accenture Technology (18.36 mln.eur), SIA Lattelecom Technology (19.13 million euros) and AS "Exigen Services Latvia" (12.34 million euros). However, the main activity of these companies is the implementation of various IS systems, which are based essentially on programming according to customer's individual requests or working with the public sector and BI services are only secondary services. 
5) The largest and most experienced company in this field in Latvia is Scandic Fusion Ltd (2016 turnover: 1.71 million euros), which provides only BI services. It is a leading expert in the field with 11 years of experience.

6) Globally medium and large companies generally need BI systems, and sometimes small ones, but it depends on the particular business area, the amount of data analysed and other factors.

7) Given the fact that it is precisely medium and large companies that are most in need of business analytics, it is concluded that the market niche is significantly limited. According to CSB data for 2015 , it can be concluded that in Latvia there were only $1.07 \%$ such enterprises in general 1'603 (0.93\%) medium sized enterprises and only $238(0.14 \%)$ large enterprises.

8) To maintain the pace of growth and ensure that business processes do not stop BI service providers need to develop strategies for business to enter external markets.

\section{Bibliography}

1. Alaskar, T., Efthimios, P. (2015). Business Intelligence Capabilities and Implementation Strategies. International Journal of Global Business, 8 (1), pp. $34-45$.

2. Bemberis, A. (2017). The interview with Gita Kolerte, at SAP LATVIA office, Riga, 24.10.2017.

3. Central Statistical Bureau of Latvia (2017). Key Business Indicators for ICT sector Companies. Retrieved: http://data.csb.gov.Iv/pxweb/lv/zin/zin_datoriz_ikt_sektors/IT0230_29.px/?rxid=cdcb978c-22b0-416aaacc-aa650d3e2ce0 Access: 15.05.2017.

4. Central Statistical Bureau of Latvia (2017). Statistical classification of economic activities in the European Community, Rev. 2. Retrieved: http://www.csb.gov.Iv/node/29900/list/4/0 Access: 01.06.2017.

5. Central Statistical Bureau of Latvia (2017). Market-based economically active enterprises in statistical regions, cities and districts by size group of enterprises by number of employees and main types of business (NACE 2. red.). Retrieved:

http://data.csb.gov.Iv/pxweb/lv/uzreg/uzreg_ikgad_01_skaits/SR00431.px/?rxid=562c2205-ba57-4130b63a-6991f49ab6fe Access: 07.10.2017.

6. Evans, J. R. (2015). Modern Analytics and the Future of Quality and Performance Excellence. QMJ, Vol. 22, No. 4 , pp. $7-17$.

7. Hocevar, B., Jaklic, J. (2010). Assessing benefits of Business Intelligence systems. Management, Vol. 15, pp. $87-119$.

8. Kreslins, K., Meijere, S. (2016). Information and communication technologies. Latvia's competitiveness report 2015. Retrieved: http://certusdomnica.Iv/wp-content/uploads/2015/07/CertusZinojums_2015_7nodala.pdf Access: 31.05.2017.

9. Ministry of Economy of the Republic of Latvia (2017). Business environment. Retrieved: https://www.em.gov.Iv/lv/nozares_politika/nacionala_industriala_politika/uznemejdarbibas_vide_/ Access: 16.05.2017.

10. Lursoft statistics and databases (2017). Sectoral financial ratios. Retrieved: https://www.lursoft.Iv/lapsaext?act=URNACEFINK Access: 03.06.2017.

11. TechTarget (2014). About Business intelligence. Retrieved: http://searchdatamanagement.techtarget.com/definition/business-intelligence Access: 06.05.2017.

12. Vitols, K. (2017). The interview with Gita Kolerte, at Scandic Fusion office, Riga, 18.10.2017.

13. World Economic Forum (2017). Insight Report. The Global Competitiveness Report 2016-2017. Retrieved: https://www.weforum.org/reports/the-global-competitiveness-report-2016-2017-1 Access: 25.09.2017.

14. World Trade Organization (2017). WTO trade topics, I-TIP services and Statistics. Retrieved: http://itip.wto.org/services/Search.aspx Access: 05.09.2017. 